\title{
ASPECTOS TÉCNICOS, ÉTICOS E LEGAIS na elaboração do prontuário médico-veterinário
}

\section{Technical, ethical and legal aspects in the preparation of the veterinary medical record}

\author{
Juliana Santeramo루 ${ }^{1}$ Tália Missen Tremori² e ${ }^{\circledR}$; Adriana de Siqueira ${ }^{4}$ \\ *Autor Correspondente: Juliana Santeramo, Rua Inula, 79 - São Miguel Paulista, \\ São Paulo, SP, Brasil. CEP: 08040-760 \\ E-mail: santeramo.juliana@gmail.com
}

Como citar: SANTERAMO, Juliana; TREMORI, Tália Missen; SIQUEIRA, Adriana de. Aspectos técnicos, éticos e legais na elaboração do prontuário médico-veterinário. Revista de Educação Continuada em Medicina Veterinária e Zootecnia do CRMV-SP, São Paulo, v.19, n. 1, 2021, e38094. Doi 10.36440/recmvz.v19i1.38094

Cite as: SANTERAMO, Juliana; TREMORI, Tália Missen; SIQUUEIRA, Adriana de. Technical, ethical and legal aspects in the preparation of the veterinary medical record. Journal of Continuing Education in Veterinary Medicine and Animal Science of CRMV-SP, São Paulo, v.19, n. 1, 2021, e38094. Doi 10.36440/recmvz.v19i1.38094

\section{Resumo}

O prontuário, documento que compila toda a história clínica de um paciente, deve incluir todos os procedimentos médicos realizados e todos os documentos pertinentes ao seu atendimento. Ainda há muitas falhas no preenchimento e elaboração de prontuários e na Medicina Veterinária os estudos acerca desse tema ainda são escassos. 0 presente trabalho apresenta a correta estruturação desse documento, relaciona as informações que nele devem ser contempladas e trata da elaboração dos termos de consentimento livre e esclarecido. Também é discutida a importância do desenvolvimento de uma normatização de prontuário unificado para que o paciente possa ser atendido em qualquer estabelecimento, e para que o seu prontuário esteja disponível para o médico-veterinário que o atenda. 0 uso do prontuário e a sua relação com o Código de Defesa do Consumidor torna evidente o quanto o prontuário pode amparar o médico-veterinário em sua rotina, inclusive no caso de eventual interposição de defesa na esfera judicial, em que o profissional é acusado de ter cometido erros na condução das suas atividades técnicas. 0 trabalho pretende ser um alerta para que os profissionais atentem para a importância da elaboração e do adequado preenchimento do prontuário e também apresenta uma proposta da implantação de um prontuário médico-veterinário unificado.

Palavras-chave: Código de ética. Erro médico-veterinário. Processo judicial. Medicina Veterinária Legal. Deontologia.

\footnotetext{
1 Pós-graduanda em Direito Ambiental, Universidade Cruzeiro do Sul (Unicsul), São Paulo, SP, e em Medicina Veterinária Legal, Faculdade Qualittas, São Paulo, SP, Brasil

2 Docente do curso de Medicina Veterinária, Centro Universitário Campo Limpo Paulista (UNIFACCAMP), Campinas, SP, e da Universidade Metodista de Piracicaba (Unimep), Piracicaba, SP, Brasil

3 Membro da Comissão Técnica de Medicina Veterinária Legal do CRMV- SP, São Paulo, SP, Brasil

4 Docente do curso de Medicina Veterinária, Universidade Cruzeiro do Sul (Unicsul), São Paulo, SP, Brasil
} 


\section{Abstract}

The medical record is a document that compiles the entire clinical history of a patient, which is based on all medical procedures performed and must include all of the relevant documents of the case. It is seen that nowadays there are still many drawbecks in filling and preparing medical records and that in Veterinary Medicine the discussion of this topic is very scarce. This work presents how should be the correct structure of this document, what information it must contain and how the proper terms of free and informed consent could be elaborated. The importance of developing a standardized medical record is discussed, so the patient could be attended in any establishment, and his record would be available to the veterinarian. The use of the medical record and its relationship with the consumer protection code, elucidates how the medical record correctly filled could assist the professional in his routine, and also when he needs to perform his defense in the judicial sphere, as in the case of accusation of a veterinary medical error. The paper was written to keep the professionals informed about the importance of preparing and filling out the medical record, and also presents a proposal for a unified veterinary medical record.

Keywords: Code of ethics. Veterinary medical error. Judicial process. Veterinary Forensic Medicine. Deontology.

\section{Introdução}

O prontuário é um documento que compila toda a história clínica de um paciente. Essa história clínica consiste na estruturação organizada dos procedimentos médicos realizados incluindo todos os documentos pertinentes ao atendimento do animal (FRANÇA, 2017) e apresentando todas as fases da evolução do atendimento clínico, desde as primeiras manifestações clínicas observadas, os exames solicitados e procedimento cirúrgico, quando executado, dentre outros (PRESTES; RANGEL, 2007).

Na Medicina Veterinária, o prontuário é definido como a documentação produzida na prática da clínica veterinária, que serve como fonte de informação sobre o paciente. Os dados coligidos no prontuário documentam o caso e possibilitam o seu estudo e respectivo controle administrativo, além de constituírem a base jurídica, como prova documental em situações de litígio judicial (HAMMERSCHMIDT, 2017).

Nos cursos de graduação em Medicina Veterinária deficitários, durante a formação dos profissionais, é oferecida uma escassa orientação sobre o correto preenchimento do prontuário, e, com isto, muitos profissionais não elaboram ou até não possuem o prontuário de seus pacientes ou, ainda, o apresentam de forma incompleta (CONCEIÇÃO; ALMEIDA; MARCON, 2017).

A importância da assinatura do termo de consentimento livre e esclarecido pelo proprietário é tamanha que na Resolução CFMV no 1.321, de 24 de abril de 2020, o Conselho Federal de Medicina Veterinária propõe modelos e estabelece a obrigatoriedade do uso de tais termos. Esses documentos devem compor o prontuário do paciente e precisam ser reproduzidos em duas vias, das quais uma fica em posse do proprietário do animal e a outra com o estabelecimento ou com o médico-veterinário responsável (BRASIL, 2020).

O prontuário pode ser elaborado de forma manuscrita e/ou digitalizada. A manuscrita é a mais tradicional, em que todos os dados, por óbvio, são registrados à mão, e os critérios para seu uso são uma caligrafia legível, à caneta, não sendo permitidas rasuras ou o uso de métodos para correção, contendo o número de registro e assinatura do profissional responsável pelo seu preenchimento (HAMMERSCHMIDT, 2017). O prontuário digital trouxe maior agilidade para o acesso às informações do paciente, economia de espaço e também possibilitou a anexação de documentos, resultados de exames e fotografias (MARTINS; LIMA, 2014; HAMMERSCHMIDT, 2017). Entretanto, quando o prontuário digital é utilizado, o software disponível deverá permitir a elaboração de cópias de segurança e possuir acesso restrito e protegido por senhas. Mesmo com o uso de prontuários digitais, recomenda-se o uso de alguns documentos impressos como os termos de: denegação, consentimento livre e esclarecido, retirada do padecente sem alta médica, dentre outros, e particularmente incluir a assinatura do proprietário (MALACARNE, 2008). 
O prontuário é tão importante que os Conselhos Regionais de Medicina (CRMs) estabeleceram que todos os estabelecimentos e/ou instituições de saúde que prestam assistência médica são obrigados a ter uma Comissão de Revisão de Prontuários, que revise os itens obrigatórios do documento. Dentre os quais merece destaque: identificação do paciente; dados de anamnese, exame físico, exames complementares, diagnósticos, prognósticos e tratamentos; evolução clínica diária, descrevendo todos os procedimentos realizados e identificando todos os profissionais envolvidos no atendimento, incluindo assinaturas e registros dos profissionais envolvidos ao longo da evolução clínica do paciente (BRASIL, 2002).

Tudo o que for relacionado ao paciente deve estar registrado no prontuário, o que constitui uma garantia para o médico-veterinário em termos de finalidades legais na justiça comum, bem como para a composição da sua defesa no caso de julgamento de processos éticos. No Manual de Responsabilidade Técnica do Conselho Regional de Medicina Veterinária do Estado de São Paulo (CRMV-SP), consta: "o que não está registrado não foi executado" (BOSCH, 2015).

0 objetivo desse trabalho é salientar a importância do prontuário em diversas áreas da Medicina Veterinária, bem como cotejar os prontuários elaborados da Medicina Humana e da Medicina Veterinária, sugerindo o aperfeiçoamento desse documento.

\section{Revisão de literatura}

O conceito de prontuário vem do latim promptuarium e é definido como "lugar onde coisas importantes são guardadas e encontradas quando for preciso", fonte de informações úteis, documento que contém dados de um paciente. Os termos ficha, registro e arquivo também se referem ao prontuário (MICHAELIS, 2008).

O prontuário médico deve ser o conjunto padronizado, organizado e sucinto de documentos, baseado no registro de todos os procedimentos médicos realizados e os documentos pertinentes ao caso atendido (FRANÇA, 2017). É um documento que se refere ao histórico clínico ou à biografia médica do paciente, sendo um meio de comunicação entre equipes profissionais, além de, em essência, possuir cunho legal (MESQUITA; DESLANDES, 2010). Na Figura 1 é apresentada uma comparação conceitual dos prontuários médico e médico-veterinário.

Figura 1: Definição de prontuário na Medicina e na Medicina Veterinária

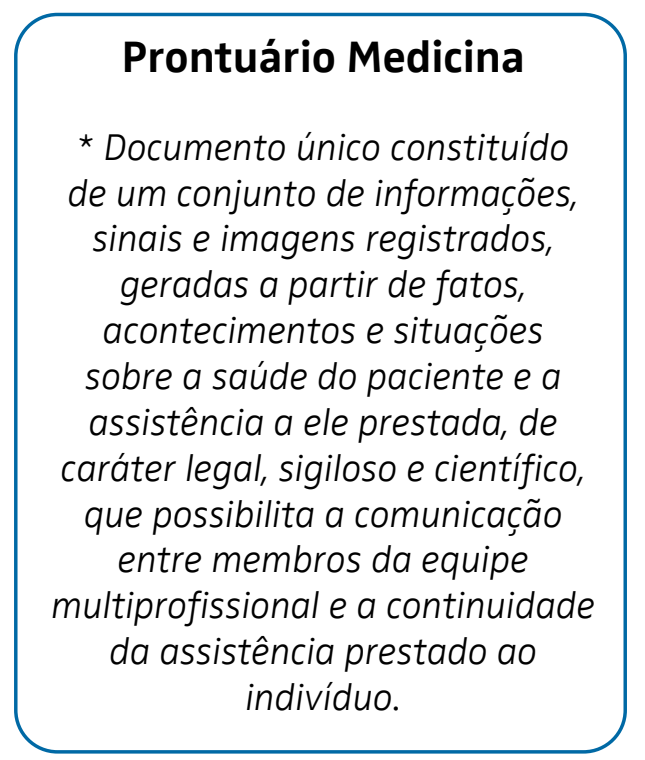

\section{Prontuário Medicina Veterinária}

* A documentação produzida na prática da clínica veterinária que deve observar os critérios técnicos, administrativos, legais e de arquivamento adequados para que possa servir como fonte de dados do animal-paciente, guardando informações que servirão para finalidades acadêmicas e administrativas, além de ter uma função como prova documental em processos éticos e/ou judiciais.

T Fonte: Adaptada de BRASIL (2002), apud SILVA (2015). 
O Conselho Federal de Medicina (CFM), na Resolução CFM no 1.638/2002, artigo 30, torna obrigatória a criação de Comissões de Revisão de Prontuários nos estabelecimentos e/ou instituições de saúde onde se presta assistência. 0 artigo 40 informa que a comissão será criada por escolha da direção do estabelecimento, devendo ser coordenada por um médico. No artigo 50 está assentado que é função da Comissão de Revisão: observar os itens que deverão constar obrigatoriamente do prontuário confeccionado em qualquer suporte, eletrônico ou manuscrito; identificação do paciente - nome completo, data de nascimento, sexo, endereço completo, nome da mãe, naturalidade; anamnese, exame físico, exames complementares solicitados e seus resultados, hipóteses diagnósticas, diagnóstico definitivo e tratamento; evolução diária do paciente, contendo data e hora, dispondo de todos os procedimentos aos que o paciente foi submetido e da identificação dos profissionais que os realizaram, assinados eletronicamente, quando elaborados e/ou armazenados em meio eletrônico. Naqueles prontuários em suporte manuscrito é obrigatória a legibilidade da letra do profissional que atendeu o paciente, bem como a identificação de todos os profissionais prestadores do atendimento. A assinatura e registro no CRM são obrigatórios. Nos casos emergenciais, em que seja impossível a colheita de pormenorizada história clínica do paciente, deverão constar: relato médico completo de todos os procedimentos realizados e que tenham possibilitado o diagnóstico e/ou a remoção para outra unidade; assegurando a responsabilidade do preenchimento, guarda e manuseio dos prontuários, que cabem ao médico assistente, à chefia da equipe, à chefia da clínica e à direção técnica da unidade (BRASIL, 2002).

Como exemplo de prontuário da Medicina Humana (Figura 2) pode-se citar aquele utilizado pelo Sistema Único de Saúde (SUS), que é considerado um dos maiores sistemas públicos de saúde do mundo (SILVA; TAVARES-NETO, 2007; OZORIO, 2016).

Figura 2: Sistema Único de Saúde - Prontuário
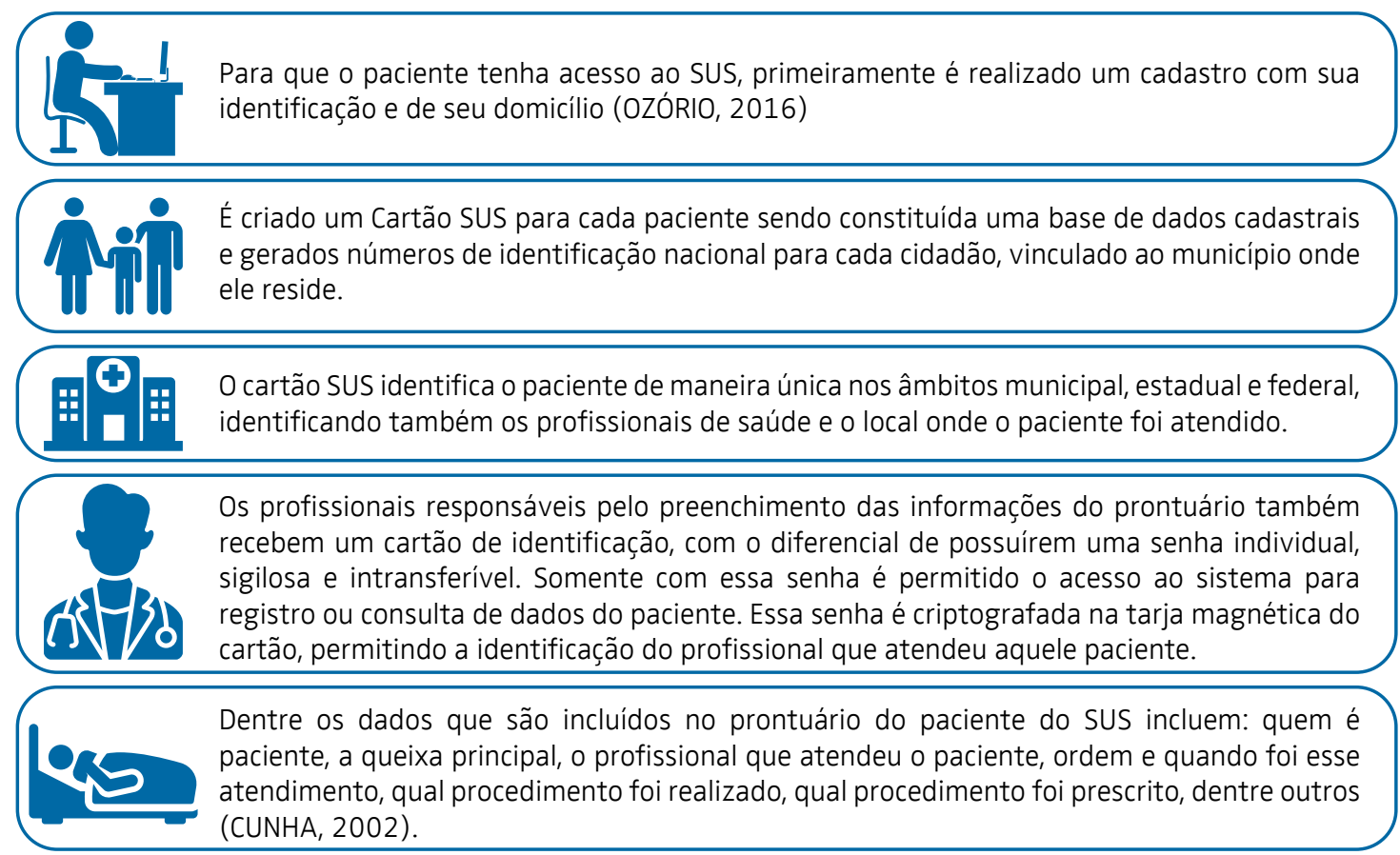

A finalidade do cartão SUS é de identificar unicamente o paciente e disponibilizar para a equipe todos os procedimentos realizados nas unidades de saúde, seja na área administrativa, filantrópica ou privada, que prestam atendimento ao SUS (OZORIO, 2016).

T Fonte: Adaptado de CUNHA (2002); OZÓRIO (2016). 


\section{Modalidade de prontuário}

A ideia de elaboração do prontuário foi proposta para que os profissionais relembrassem a história clínica do paciente. 0 modelo de prontuário manuscrito, proposto em 1880, trazia muitas informações sobre os pacientes, coligidas em documento único, levando à dificuldade na localização das informações. Em 1907, foi adotado um modelo de registro individual, originando o prontuário médico do paciente. Com os avanços de sistemas informatizados na área da saúde, surge o Prontuário Eletrônico do Paciente (PEP), com uma nova proposta de união de dados sobre sua saúde e os cuidados durante todo seu tempo de vida (MARIN; MASSAD; AZEVEDO NETO, 2003).

\section{Prontuário manuscrito}

É o formato tradicional, pois nele todos os dados colhidos do animal são escritos à mão com caligrafia legível. Deve ser escrito à caneta, não é permitido o uso de corretor e não pode haver qualquer sinal de rasura. 0 seu uso é restrito a informações sobre o paciente. Deve conter número dos registros e assinaturas dos profissionais que preencheram o documento (HAMMERSCHMIDT, 2017).

\section{Prontuário eletrônico ou digital do paciente}

Devido aos avanços da tecnologia da informação, o prontuário eletrônico trouxe maior agilidade ao acesso dos dados clínicos sobre o paciente, propiciando: economia de espaço, facilidade para a realização de impressões e para a atualização de informações (MARTINS; LIMA, 2014). Também possibilita a integração de outros recursos como digitalização de documentos, resultado de exames e material iconográfico com finalidade de documentação de lesões ou de outros achados clínicos (HAMMERSCHMIDT, 2017).

Destaca-se, contudo, que por questões de segurança e de arquivo, os requisitos que devem ser observados para o uso de um prontuário eletrônico incluem: necessidade de sistemas capazes de garantir a segurança, autenticidade, confidencialidade e integridade dos dados, com mecanismo de acesso restrito e limitado, com a manutenção da privacidade das informações e o sigilo profissional.

Uma das finalidades (Figura 3) do prontuário eletrônico é a de oferecer mais recursos para que o profissional responsável o preencha. Estão disponíveis alguns softwares que propõem uma linguagem padronizada e estruturada, recuperação da informação com maior velocidade e o acesso simultâneo entre vários usuários, inclusive em diferentes lugares, além da transmissão de dados. Porém, é importante que o uso dos dados manuscritos seja mantido. A título de exemplo, pode-se citar o Termo de Consentimento Livre e Esclarecido, que contém a assinatura do proprietário do animal (MALACARNE, 2011). Os prontuários eletrônico e manuscrito devem ser utilizados em conjunto, não devendo ser um substituído pelo outro. 
Figura 3. Áreas de aplicação do prontuário na Medicina Veterinária

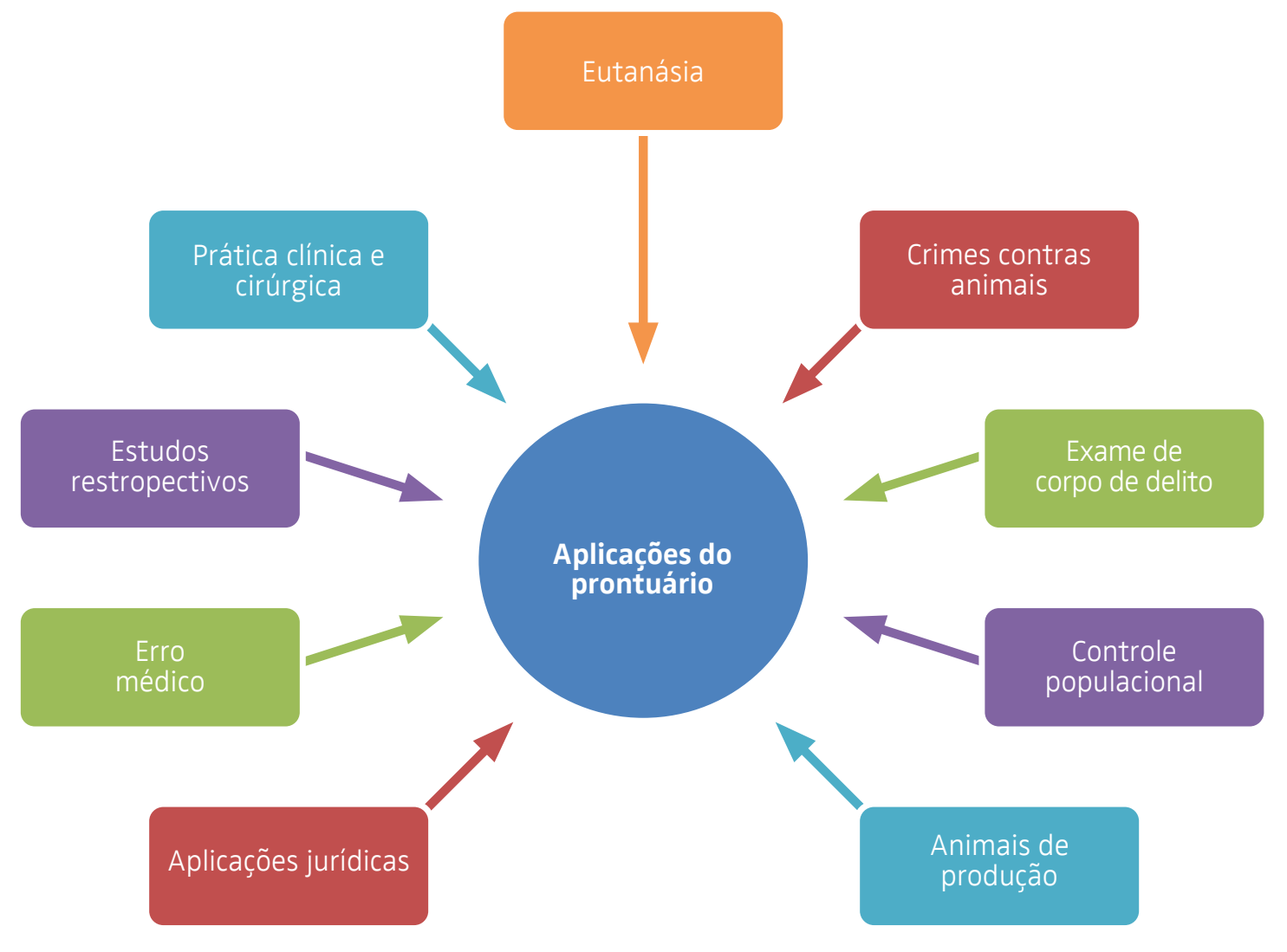

T Fonte: Adaptada de HAMMERSCHMIDT (2017).

A responsabilidade da elaboração do prontuário é do médico-veterinário, conforme versa o artigo 80 do Código de Ética de Medicina Veterinária, Resolução CFMV no 1.138 de 2016, em que é vedado ao médico-veterinário:

IX - deixar de elaborar prontuário e relatório médico-veterinário para casos individuais e de rebanho, respectivamente (BRASIL, 2016).

A elaboração de um prontuário é algo que parece fácil, porém, na prática, há profissionais que apresentam o prontuário com dados incompletos, imprecisos, não o elaboram, não possuem, ou guardam o prontuário do seu paciente. 0 prontuário é um documento de extrema importância, pois nele é disponibilizado todo histórico de saúde de um animal ou de um rebanho/plantel (BRASIL, 2020).

O não tão novo Código de Ética Médica-veterinária, Resolução CFMV no 1071/2015 informa que o prontuário do paciente pertence ao cliente e caso ele o solicite, o médico-veterinário deverá imediatamente fornecer uma cópia ou um relatório fiel que contenha todos os dados do prontuário, conforme o que é disposto no seu artigo 8, o médico-veterinário não deve:

XI - deixar de fornecer ao cliente, quando solicitado, laudo médico-veterinário, relatório, prontuário, atestado, certificado, resultados de exames complementares, bem como deixar de dar explicações necessárias à sua compreensão (BRASIL, 2015). 
Segundo a Resolução do CFMV no 1071/2015, no artigo 6: A solicitação expressa de cópia de prontuário clínico, realizada pelo responsável do animal ou por representante legal, deve ser atendida de imediato e devidamente registrada no serviço veterinário (BRASIL, 2015).

Na mesma resolução, no artigo $1^{\circ}$, consta que: "as informações contidas no histórico do prontuário devem expressar todos os procedimentos realizados no paciente".

Portanto, é tácita a obrigação do médico-veterinário fornecer toda documentação solicitada prontuário, certificado, atestado, relatório, dentre outros - para a comprovação documental de todo serviço prestado (CONCEIÇÃO, ALMEIDA; MARCON, 2017).

O prontuário médico-veterinário é um documento sigiloso que contém informações dos pacientes e dados cadastrais dos clientes, devendo ser utilizado somente para o exercício da profissão, preservando-se o sigilo profissional. Sendo assim, baseado no Artigo $11^{\circ}$ do Código de ética, o médico veterinário não deverá:

IV - facilitar manuseio e conhecimento dos prontuários, relatórios e demais documentos sujeitos ao segredo profissional (BRASIL, 2017).

\section{Aplicações do prontuário}

O prontuário é um instrumento valioso para o cliente, já que contém todas as informações sobre o estado de saúde do padecente e é importante para o médico-veterinário como meio auxiliar à sua defesa no caso de processos éticos instaurados em autarquias, em demandas em órgãos de defesa do consumidor ou em instâncias jurídicas. Seu preenchimento adequado, seja para qual for a sua finalidade, é de extrema importância. Ao prestar assistência a um paciente, o médico-veterinário deve elaborar um prontuário em ordem cronológica em seu histórico, que deve ser esclarecedor, organizado, registrado em adequada nomina clínica e dispondo todos os achados dos exames físico e complementares do animal (HAMMERSCHMIDT, 2017).

O prontuário, também, deve ser utilizado para o controle de custos e cobranças dos serviços prestados (SLOWINSKI et al, 2016; HAMMERSCHMIDT, 2017). No ambiente acadêmico, o prontuário corretamente preenchido intensifica o aprendizado, pois o estudante poderá acompanhar toda a evolução do caso do paciente, desde o primeiro atendimento, prognóstico, tratamentos até a resolução do caso (HAMMERSCHMIDT, 2017).

É essencial que o prontuário esteja completo e atualizado. Certamente é o documento mais importante em caso de questionamento da conduta do profissional médico-veterinário, pois muitas vezes é o único que pode comprovar o estado que o paciente se encontrava quando do(s) atendimento(s) (SLOWINSKI et al, 2016). Portanto, o prontuário médico é um documento assaz relevante para reunir provas técnicas necessárias para defesa do profissional (PRESTES; RANGEL, 2007).

0 prontuário deve conter toda a informação referente ao paciente e aos serviços que foram prestados, conforme o disposto na Figura 2. Na Figura 4, estão elencados os itens que deverão ser contemplados no prontuário médico-veterinário, baseados na Resolução CFMV no 1321/2020. 
Figura 4. Aplicações do prontuário na Medicina Veterinária

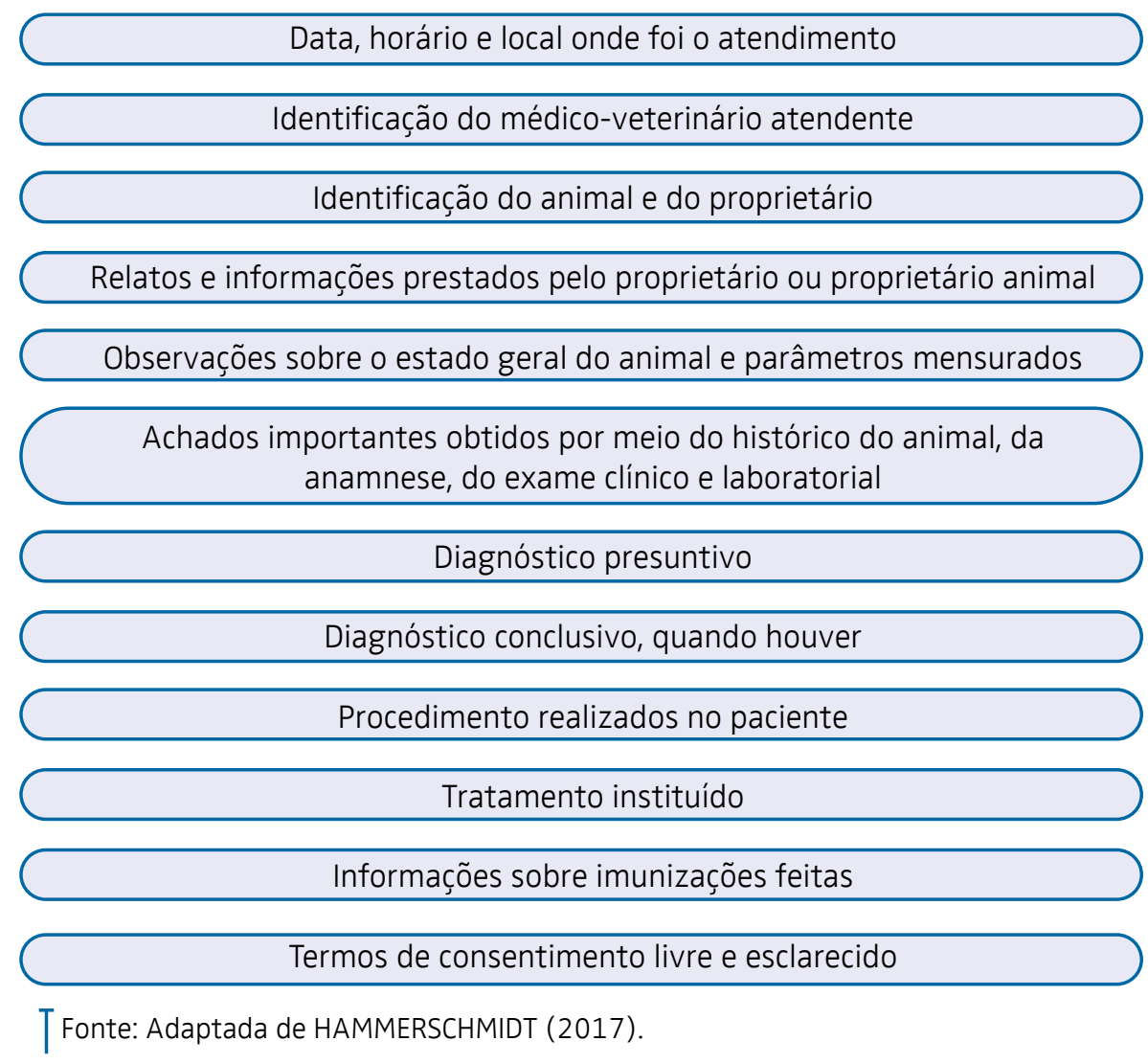

A Resolução CFMV no 1321/2020 reiterou a informação de que a solicitação pelo cliente de cópia de prontuário deverá ser atendida de imediato, devendo ser anexados todos os tipos de exames complementares realizados. A guarda do prontuário deve ser mantida pelo período mínimo de cinco anos, contados a partir do último atendimento realizado no animal, mesmo em caso de óbito. Nesse caso, o atestado de óbito deve ser entregue ao proprietário do animal, devendo uma via ser anexada ao prontuário.

Em casos de atendimento emergencial que configure risco iminente de morte, os procedimentos podem ser realizados independentemente do prévio consentimento do cliente. Ratifica-se, ainda, que para a retirada de um paciente de serviços veterinários sem alta médica, o proprietário do animal deverá assinar o termo de esclarecimento, no caso de recusa, deve ser solicitada a assinatura de duas testemunhas e registrado todo o ocorrido no prontuário, ficando o médico-veterinário desobrigado a prescrever qualquer tipo de terapêutica nesses casos. Os modelos de termos e autorizações propostos podem ser adaptados conforme a realidade do estabelecimento desde que sejam mantidos os dados básicos de informação (BRASIL, 2020).

\section{Documentos médico-veterinários}

Todos os documentos devem conter os dados básicos, ser impressos e firmados em duas vias, uma das quais ficará em posse do cliente e a outra com o médico-veterinário. Esses documentos devem ser anexados ao prontuário do paciente. As Figuras 5, 6 e 7 realçam, respectivamente, os dados básicos dos prontuários, a definição dos documentos que o compõem e incluem outros documentos recomendados e elencados no Manual de Responsabilidade Técnica. 
Figura 5: Dados Básicos do Prontuário

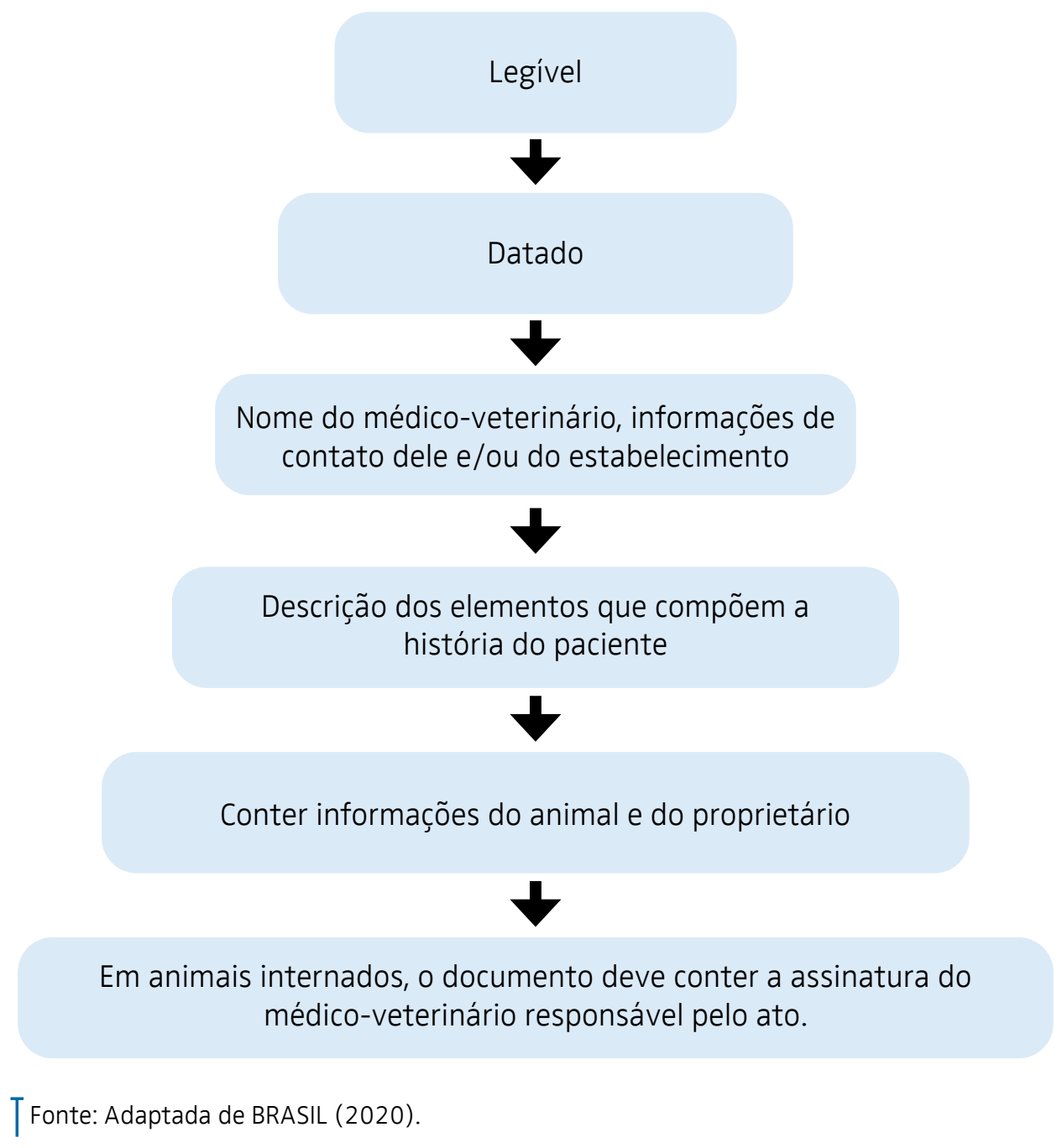

Figura 6: Definição dos documentos que compõem o prontuário

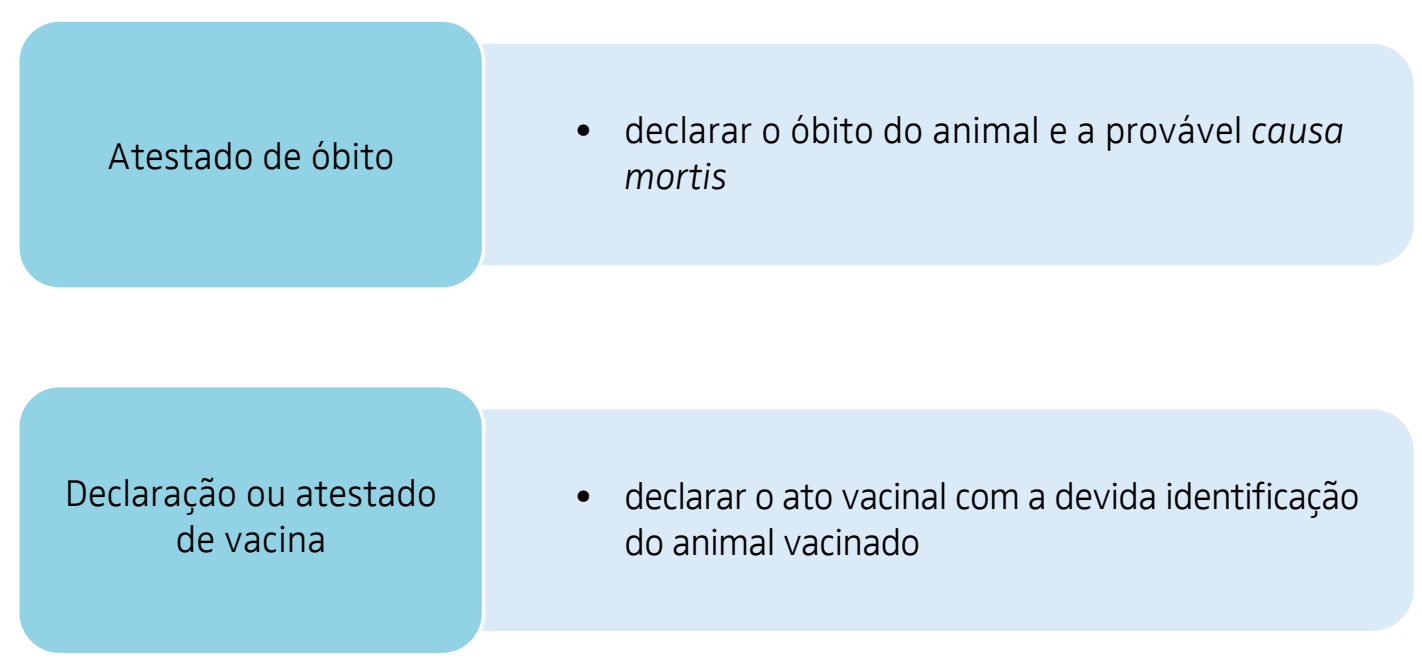


Atestado sanitário ou de saúde animal
- declarar o estado ou condição de saúde do animal

Carteira de vacinação

- registro de todos os atos vacinais realizados no animal

Termo de consentimento livre e esclarecido para realização de exames
- formalizar a ciência e livre consentimento ou autorização para realização de exames veterinários
Termo de consentimento livre e esclarecido para realização de procedimento terapêutico de risco
- formalizar a ciência e livre consentimento ou autorização para realização de procedimento terapêutico que tenha elevado grau de comprometimento ou perda de sentido ou função, debilidade ou deformidade, bem como óbito

\section{Termo de consentimento livre e esclarecido para retirada de corpo de animal em óbito}

- esclarecer e transferir a esse a responsabilidade pela posse e destinação ambiental adequada do cadáver

\section{Termo de consentimento livre e esclarecido para realização de procedimento cirúrgico}

- formalizar a ciência e livre consentimento ou autorização para realização de procedimento cirúrgico

\section{Termo de consentimento livre e esclarecido para realização de internação e tratamento clínico ou pós-cirúrgico}

- formalizar a ciência e livre consentimento ou autorização para realização de internação e tratamento clínico ou pós-cirúrgico 
Termo de consentimento livre e esclarecido para realização de procedimentos anestésicos
- formalizar a ciência e livre consentimento ou autorização para realização de procedimentos de anestesia
Termo de consentimento livre e esclarecido para realização de eutanásia
- formalizar a ciência e livre consentimento ou autorização para realização de eutanásia no animal
Termo de esclarecimento para a retirada de animal do serviço veterinário sem alta médica
- esclarecimento e obtenção da manifestação de livre intenção de retirada do animal de serviço veterinário sem alta médica, bem como de assunção de plena e irrestrita responsabilidade sobre os riscos sanitários e de morte do animal

\section{Termo de} consentimento livre e esclarecido de doação de corpo de animal para ensino e pesquisa
- esclarecimento e obtenção da manifestação de livre doação do corpo do animal para encaminhamento à instituição de ensino e pesquisa
Termo de consentimento para realização de pesquisa clínica
- esclarecimento e obtenção de autorização de submissão do animal a estudo ou pesquisa

T Fonte: Adaptada de BRASIL (2020).

Figura 7: Outros documentos recomendados pelo Manual de Responsabilidade Técnica

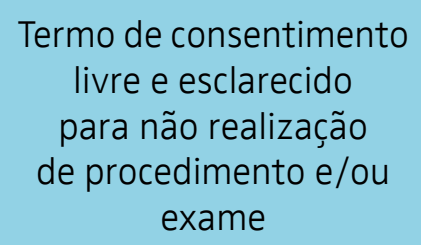

- formalizar a ciência e livre consentimento para não realização de procedimento e/ou exame 
Termo de consentimento livre e esclarecido para não aceitação de conduta e/ou

- formalizar a ciência e livre consentimento para medicações não aceitação de conduta e/ou medicações

Carta de encaminhamento
- informar ao colega sobre histórico do animal que está encaminhando

\section{Termo de consentimento livre e esclarecido para reconhecimento de dívida}

- formalizar a ciência e livre consentimento de reconhecimento de dívida

T Fonte: Adaptada de BRASIL (2020).

\section{0 médico-veterinário e o Código de Defesa do Consumidor}

Perante o Código de Defesa do Consumidor (CDC), o profissional está sujeito às regras de relação de consumo, isso significa que, o médico-veterinário é o prestador de serviços e o cliente/proprietário do animal é o consumidor (SLOWINSKI et al. 2016).

Profissões da área da saúde são consideradas de risco, nele se inclui todos os circunstantes envolvidos. Uma falha no atendimento será atribuída a um responsável, o qual deve reparar o prejuízo causado desde que comprovado o dolo, a culpa e o nexo de causalidade entre o dano e a conduta profissional, aqui se inclui, também, a responsabilidade civil, ética e penal do profissional (MALACARNE, 2008).

Conforme é mencionado no artigo 10, do código de ética vigente, o médico-veterinário "deve exercer a profissão com o máximo de zelo e o melhor de sua capacidade" (Resolução CFMV no 1.138/2016), não havendo obrigatoriedade de obtenção de um resultado adequado e esperado específico (SLOWINSKI et al, 2016). O médico-veterinário deve sempre esclarecer ao proprietário do animal todas as questões envolvidas no atendimento, fazendo o registro no prontuário, disponibilizando opções para o tratamento, elucidando os riscos envolvidos em cada situação, permitindo que este tome a decisão em optar ou não por um procedimento, fornecendo os termos de consentimento livre e esclarecido para sua assinatura (BOSCH, 2015). Caso o cliente opte por não realizar o procedimento, ele deverá firmar um termo informando que tomou ciência da importância do procedimento, mas que mesmo assim não autorizou a sua realização (SLOWINSKI et al. 2016). Entretanto, há aqueles que se recusam peremptoriamente a assinar esse documento e, se isso ocorrer, o profissional deverá registrar as informações no prontuário e colher a assinatura de duas pessoas a título de testemunho. Quando os clientes não acatam as recomendações do médico-veterinário, ele pode retirar a sua assistência o que está em consonância com o disposto no Código de Ética do Médico-veterinário, Capítulo III, Artigo 5, onde é destacado que o profissional poderá: 
Escolher livremente seus clientes ou pacientes, com exceção dos seguintes casos: quando não houver outro médico-veterinário para atendimento, quando outro colega solicitar sua colaboração, em casos de emergência ou perigo para a vida do animal ou do homem. (BRASIL, 2018)

Exceto nas situações suprarreferidas, o médico-veterinário pode recusar seu atendimento sem ferir a ética profissional (CONCEIÇÃO; ALMEIDA; MARCON, 2017).

Os termos de consentimento livre e esclarecido devem estar sempre anexados ao prontuário do animal, provando uma eventual decisão voluntária do cliente, após ter sido adequadamente informado sobre os procedimentos que deverão ser realizados no animal (MALACARNE, 2008).

\section{Aplicações práticas do prontuário médico-veterinário}

\section{Jurídicas}

Frente às ações de responsabilidade civil, o prontuário médico-veterinário possui todo acervo documental do paciente afora os procedimentos realizados pelo profissional. Mesmo quando o paciente está sob cuidados de uma equipe multiprofissional, o prontuário médico deve ser adequadamente preenchido e atualizado por todos os envolvidos em suas respectivas atuações (PRESTES; RANGEL, 2007).

\section{Erro médico-veterinário}

É definido como o dano provocado à saúde do paciente sem a intenção de cometê-lo, ou seja, sem o dolo. Trata-se de conduta profissional inadequada, que pode produzir dano ao paciente, decorrente de imperícia, imprudência ou negligência. Constitui-se na falha do profissional no exercício de seu mister (FRANÇA, 2017).

O erro profissional está ligado à responsabilidade civil, regulamentado pelo CDC e pelo Código Civil, gerando o dever do profissional de reparar o dano causado por ato próprio, à pessoa ou coisa que dela dependa (MARQUES, 2014).

São necessários alguns componentes fundamentais para que o erro médico seja caracterizado: o dano, a ausência de dolo e o nexo de causalidade, relacionando a conduta inadequada do médico e as suas consequências (MALACARNE, 2008).

0 nexo de causalidade é a relação de causa e efeito entre a ação e o dano, já a culpa está relacionada ao dano provocado sem a intenção de prejudicar alguém (BOSCH, 2015). A falta de cuidados, zelo, rapidez, presteza também caracterizam culpa (FRANÇA, 2017).

O Artigo 9o da Resolução CFMV no 1.138 de 2016, que trata da responsabilidade profissional do código de ética de Medicina Veterinária, estabelece que:

\footnotetext{
O médico-veterinário será responsabilizado pelos atos que, no exercício da profissão, praticar com dolo ou culpa, respondendo civil e penalmente pelas infrações éticas e ações que venham a causar dano ao paciente ou ao cliente e, principalmente:

I- praticar atos profissionais que caracterizem imperícia, imprudência e negligência (BRASIL, 2016).
}

Diante de uma alegada acusação de erro médico-veterinário, a solicitação de indicação de um perito médico-veterinário é de fundamental importância para a avaliação do nexo causal, investigando a atitude tomada pelo profissional e o suposto erro médico (CONCEIÇÃ̃); ALMEIDA; MARCON, 2017). 
Durante a investigação, a culpa do profissional acusado deverá estar explícita em uma ou mais de suas modalidades, que são a negligência, caracterizada pela falta de cuidado; a imprudência, caracterizada pela ação irresponsável; e a imperícia, caracterizada pela falta de habilidade (CONCEIÇÃO; ALMEIDA; MARCON, 2017; HAMMERSCHMIDT, 2017).

Não são raros casos de imperícia, negligência e imprudência na prática médica-veterinária, e o prontuário é um documento-chave no curso da investigação de todo acontecimento (HAMMERSCHMIDT, 2017).

A resposta de um médico-veterinário que teve sua conduta questionada deverá ter respaldo por registros médicos confiáveis e claros (FALL, 2014). Em caso de processos judiciais, o profissional acusado deverá provar que agiu conforme o que está tecnicamente recomendado, que agiu com ética e profissionalismo para aquela situação, porém não basta apenas a descrição do médico sobre todo o ocorrido, são necessários também os demais termos de consentimento assinados pelo cliente (HAMMERSCHMIDT, 2017).

Se o médico-veterinário for acusado por erro médico, um documento de extrema importância para sua defesa é o prontuário, pois é nele que está incluída a história clínica do paciente com detalhes do atendimento. Devido à dificuldade e controvérsias que poderão surgir sobre o caso, a perícia se torna um elemento indispensável (BOSCH, 2015). No caso de ações judiciais, a prova documental representada pelo prontuário é de grande valor para sustentar a defesa do profissional (REBELO, 2016).

Um prontuário médico bem elaborado representa afora a defesa judicial, a seriedade e a habilidade técnica do profissional envolvido. Não é incomum a detecção de discordâncias em procedimentos dispostos no bojo de prontuário e o que foi verdadeiramente realizado. São comuns também a sua redação com frases ilegíveis, rasuras e omissão de informaç̧̃̃es (PRESTES; RANGEL, 2007).

Quando há a suspeita de agravo ético, o ideal é que se colete o máximo de informações possíveis sobre o animal envolvido (ARAÚJO; BIONDO; GARCIA, 2015).

0 médico-veterinário tem a obrigação de estar sempre atento à possibilidade de cometimento de crimes contra animais, devendo registrar a suspeita ou a real constatação de maus-tratos, abuso ou principalmente crueldade no respectivo prontuário (BRASIL, 2018).

Em situações de envolvimento criminal ou suspeita, os animais devem ser submetidos à análise específica, como realização de exame de corpo de delito para a caracterização de lesões e materialização em forma de documentos, que também irão compor o prontuário (TREMORI, ROCHA, 2013).

No caso de constatação de maus-tratos, tudo deve ser registrado, organizado e arquivado em prontuário com riqueza de detalhes, utilizando a ficha de anamnese, exame físico, relatório técnico, fotografias, vídeos, exames e, se possível a consulta, deverá ser realizada com a companhia de outro profissional que poderá desempenhar o papel de testemunha (ARAÚJO, BIONDO, GARCIA, 2015).

Realizadas todas as anotações sobre a suspeita de maus-tratos, abuso e/ou crueldade, para se eximir da participação ou omissão perante o crime, junto com os dados do prontuário do animal, o médico-veterinário também deverá incluir as informações indicativas de um responsável, local, data, fatos e situações, assinando, carimbando e datando o documento, o qual deverá ser remetido de imediato ao Conselho Regional de Medicina Veterinária (CRMV), por meio físico ou eletrônico, podendo a autarquia encaminhá-lo às autoridades competentes. Se o médico-veterinário se omitir, ele cometerá infração ética (BRASIL, 2016). 


\section{Discussão}

O prontuário médico-veterinário é um documento que possui valor incontestável, ainda assim há profissionais que não o preenchem de forma correta (CONCEIÇÃO; ALMEIDA; MARCON, 2017), gerando dificuldades para a avaliação da evolução do quadro de um paciente perante um tratamento e, até mesmo, criando dificuldades para a sua defesa, caso o seu procedimento seja questionado. 0 prontuário é o documento que pode auxiliar a avaliação das condutas tomadas pelo profissional (HAMMERSCHMIDT, 2017). Diante das comparações feitas entre o prontuário médico e o médico-veterinário, questionase a possibilidade de haver uma legislação sobre a criação de comissões de revisão de prontuários na Medicina Veterinária, como ocorre na legislação estabelecida pelo Conselho Federal de Medicina (Resolução CFM no 1.638/2002), além de criação do prontuário médico-veterinário unificado, na modalidade eletrônica, como já ocorre no Sistema Único de Saúde. Contudo, devem ser consideradas as dificuldades da estruturação de uma base de dados unificada dos pacientes, seu custo, bem como as questões já levantadas no presente trabalho, como a hipótese da não adesão ao preenchimento adequado do documento pelos médicos-veterinários. Caso esse feito se concretizasse, o CFMV passaria a ter maior controle dos procedimentos médico-veterinários (SILVA; TAVARES-NETO, 2007).

Em tempos de pandemia como a atual de SARS-CoV-2, muitos clientes entram em contato com os profissionais por meio de aplicativos de texto e ligações telefônicas, com dúvidas sobre a saúde do seu animal. Esses dados também devem ser transcritos no prontuário do paciente, visto que dados importantes referentes ao padecente podem ser perdidos, se não forem registrados, e o profissional deve se manter atento para não cometer nenhuma infração ética ao prestar esse atendimento, sendo vetado receitar sem antes realizar o exame clínico do animal, como dispõe o Artigo 80, parágrafo XV do Código de Ética do Médico-veterinário.

Porém, essa é uma realidade que deve ser trabalhada e lapidada, visto que muitos estabelecimentos não fazem uso de prontuário eletrônico, não sendo possível a unificação dessa forma. Mais trabalhos devem ser realizados sobre o tema, tratando da sua importância, a fim de estruturar a formação de alicerces sólidos com vista a uma possível padronização do prontuário médico-veterinário nas suas diferentes áreas.

\section{Considerações finais}

O prontuário médico-veterinário é o principal documento comprobatório de condutas e procedimentos efetuados no atendimento clínico. Além disso, nele devem ser registradas possíveis intercorrências como, por exemplo, a não realização de um procedimento em um animal pela discordância de seu proprietário. Assim sendo, o profissional precisa se conscientizar da necessidade da observação das determinações existentes no seu código de ética, bem como das recomendações apresentadas no Manual de Responsabilidade Técnica. Atendendo a estes elementos ele estará apto para atender eventuais demandas jurídicas, atualmente, cada vez mais frequentes. Outrossim, o preenchimento adequado do prontuário é uma condição sine qua non para a avaliação clínica do paciente, o que demonstra o respeito e a responsabilidade do profissional perante o paciente, o proprietário e a classe médica-veterinária.8

\section{Referências}

ARAÚJO, G. D; BIONDO, A. W; GARCIA, R. D. C. M. Traumas não acidentais e outros abusos na rotina clínico-veterinária: como reconhecer, proceder e encaminhar. Revista Clínica Veterinária, ano XX, n. 116, maio/junho, p.100-104, 2015. 
BOSCH, R. V. Responsabilidade profissional. In: JERICÓ, M. M; KOGIKA, M. M; NETO, J. P. D. A. Medicina interna de cães e gatos. 1.ed. Rio de Janeiro: Guanabara Koogan Ltda, v. 1, p. 85-150, 2015.

BRASIL. Conselho Federal de Medicina. Resolução CFM no 1.638: criação da Comissão de Revisão de Prontuários, de 10 de julho de 2002. Define prontuário médico e torna obrigatória a criação da Comissão de Revisão de Prontuários nas instituições de saúde. Diário Oficial. Brasília, 10 jul. 2002; seção 1, p. 184-5. Disponível em: http://www.cremesp.org.br/?siteAcao=LegislacaoBusca\&nota=32. Acesso em: 12 de jun. 2020.

BRASIL. Conselho Federal de Medicina Veterinária. Resolução CFMV no 1.071, de 17 de novembro de 2014. Dispõe sobre normatização de documentos emitidos pelos serviços veterinários de clínica e cirurgia destinados aos animais de companhia, com relação a declarações, atestados, autorizações e/ ou solicitações dos responsáveis pelos animais submetidos a procedimentos. Diário Oficial. Brasília, 02 fev. 2015. Disponível em: https://www.crmvrs.gov.br/transparencia/PDFs/legislacao/R1071.pdf?. Acesso em: 12 de jun. 2020.

BRASIL. Conselho Federal de Medicina Veterinária. Resolução CFMV no 1.138. Código de Ética Médico-veterinário. Diário Oficial. Brasília, 16 dez. 2016. Disponível em: https://www.google.com/ url?sa=t\&source=web\&rct=j\&url=https://www.crmvsp.gov.br/arquivo_legislacao/Codigo_de_eticaMV.pdf\&ved=2ahUKEwiBhPPt3rfwAhU7H7kGHVA7B3YQFjAAegQIAxAC\&usg=AOvVaw2xZZbsa3ViP 93uQolK9ZPR\&cshid=1620396457473. Acesso em: 03 de mai. 2020.

BRASIL. Conselho Federal de Medicina Veterinária. Resolução CFMV no 1236. Define e caracteriza crueldade, abuso e maus-tratos contra animais vertebrados, dispõe sobre a conduta de médicos-veterinários e zootecnistas e dá outras providências. Diário Oficial. Brasília, 26 out. 2018. Disponível em: http://www3. cfmv.gov.br/portal/public/lei/download-arquivo/id/1297. Acesso em: 03 de jul. 2020.

BRASIL. Conselho Federal de Medicina Veterinária. Resolução CFMV no 1321. Institui normas sobre os documentos no âmbito da clínica médico-veterinária e dá outras providências. Diário Oficial. Brasília, 24 abr. 2020. Disponível em: http://www3.cfmv.gov.br/portal/public/lei/download-arquivo/id/1498. Acesso: 05 de jun. de 2020.

BRASIL. Conselho Regional de Medicina Veterinária de São Paulo. Manual de responsabilidade técnica e legislação. 3. ed, p. 198-207, 2014.

CONCEIÇÃO, C. D. D. C; ALMEIDA, E. C. P.; MARCON, F. M. Novo código de ética médica-veterinária: comentários sob a ótica pericial. 1.ed., Salvador, 2017.

CUNHA, R. E. D. Cartão Nacional de Saúde - os desafios da concepção e implantação de um sistema nacional de captura de informações de atendimento em saúde. Revista Ciência \& Saúde Coletiva, v.7, n.4, 869-78, 2002. DOI: https://doi.org/10.1590/S1413-81232002000400018.

DICIONÁRIO MICHAELIS. Dicionário escolar de língua portuguesa. São Paulo: Editora Melhoramentos, 2008.

FALL, M. Importance medical records. Minnesota Board of Veterinary Medicine. Newsletter, 2014. Disponível em: https://www.google.com/url?sa=t\&source=web\&rct=j\&url=https://mn.gov/boards/ass ets/Fall\%25202014\%2520Newsletter\%2520BVM tcm21-26541.pdf\&ved=2ahUKEwj9hLGcyLDwA hWOILKGHUT2BHOQFjABegQICRAC\&usg=AOvVaw1eLb6xxRlo08Wh8smG0Mqw\&cshid=162015 1137019. Acesso em 25 de janeiro de 2020.

FRANÇA, G. V. Medicina Legal. 11.ed. Rio de Janeiro: Guanabara Koogan, 2017. p. 105-106.

HAMMERSCHMIDT, J. O prontuário médico-veterinário: requisitos e importância. In: TOSTES, R. A; REIS, S. T; CASTILHO, V. V. Tratado de Medicina Veterinária Legal. 1. ed. Curitiba: MedVep, 2017. p. 120-126.

HAMMERSCHMIDT, J. Perícia em bem-estar animal nos crimes de maus-tratos contra animais. In: TOSTES, R. A; REIS, S. T; CASTILHO, V. V. Tratado de Medicina Veterinária Legal. 1.ed. Curitiba: MedVep, 2017. p. 334-357. 
MALACARNE, G. B. Prontuário clínico do médico-veterinário. Revista Jus Navigandi, ISSN 1518-4862, ano 13, n. 2003, 25 dez. 2008. Disponível em: http://jus.com.br/artigos/12120. Acesso em: 16 de jun. 2020.

MALACARNE, G. B. Responsabilidade civil do médico-veterinário. Revista Jus Navigandi, ano 13, n. 2004, 26 dez. 2008. Disponível em: http://jus.com.br/artigos/12121. Acesso em: 16 de jun. 2020.

MALACARNE, G. B. Prontuário clínico. In: PASQUALIN, C. Orientações ao médico-veterinário: manual de direitos e deveres. Curitiba: SINDIVET, 2011. p. 69-73.

MARIN, H.F, MASSAD E, AZEVEDO NETO. Prontuário eletrônico do paciente: definições e conceitos. IN: MASSAD E., MARIN H.F., AZEVEDO NETO R.S .(editores). O prontuário eletrônico do paciente na assistência informação e conhecimento médico. São Paulo: USP, 2003. p. 1-20.

MARTINS, C. LIMA, M.S. Vantagens e desvantagens do prontuário eletrônico para instituição de saúde. Revista de Administração em Saúde. v.16, n. 63, abr-jun, 2014.

MARQUES L.M. et al. Imperícia e negligência em ovário-salpingo-histerectomia de uma cadela - relato de caso. Revista Brasileira de Medicina Veterinária, v.36, n.4, p. 425-429, 2014.

MESQUITA, A. DESLANDES, S. A construção dos prontuários como expressão prática dos profissionais de saúde. Revista Saúde e Sociedade, v. 19, n. 3, jul.-set., 2010. DOl: http://dx.doi.org/10.1590/S010412902010000300017. Disponível em: https://www.scielo.br/scielo.php?script=sci_arttext\&pid=S0104$12902010000300017 \&$ Ing=pt\&tlng=pt. Acesso em: 12 de mai. 2020.

OZORIO, E. Unificação do cadastro SUS integração com a biometria digital. Tese (Doutorado em Gestão Pública), Universidade Federal do Paraná, Colombo, 2016. Disponível em: http://acervodigital.ufpr. br/bitstream/handle/1884/51436/R\%20\%20E\%20EDILSON\%20LUIZ\%200ZORIO.pdf?sequence=1. Acesso em: 23 de jun. 2020.

PRESTES, L; RANGEL, M. Prontuário médico e suas implicações médico-legais na rotina do coloproctologista. Revista Brasileira Coloproctologia, v.27, n.2, p. 154-157, 2007. DOI: https://doi. org/10.1590/S0101-98802007000200004.

REBELO, T. Prontuário médico: importante ferramenta de defesa em processos administrativos e judiciais. Revista Jus Navigandi, Teresina, ano 21, n.4738, 21 jun. 2016. Disponível em: https://jus. com.br/artigos/43293. Acesso: 03 de jun. 2020.

SILVA, F.G; TAVARES-NETO, J. Avaliação dos prontuários médicos de hospitais de ensino do Brasil. Revista Brasileira de Educação Médica [online], v. 31, n. 2, p. 113-126, ago. 2007. DOI: https://doi. org/10.1590/S0100-55022007000200002.

SILVA, A.P.T. Prontuário Médico-veterinário. In: CONCEIÇÃO, C.D.C. Perícia Cível para Médicos- veterinários. 1. ed., Rio de Janeiro: L.F. Livros, 2015. p. 78-83.

SLOWINSKI, K. et al. Responsabilidade ética e civil do médico-veterinário no ambiente hospitalar. Revista de Educação Continuada em Medicina Veterinária e Zootecnia do CRMV-SP, v. 14, n. 2, p. 30-37, 2016. DOI: https://doi.org/10.36440/recmvz.v14i2.31816.

TREMORIT. M.; ROCHAN. S. Exame do corpo de delito na Perícia Veterinária (Ensaio). Revista de Educação Continuada em Medicina Veterinária e Zootecnia do CRMV-SP, v. 11, n. 3, p. 30-35, 2013. DOI: https://doi.org/10.36440/recmvz.v11i3.17373. 